\title{
WHO IS TO BLAME
}

\author{
Rishi Ram Rijal*
}

\begin{abstract}
Learning English language and becoming English language teacher have attracted many people in our country but because of various factors only the weak intake admit in teacher education courses. The aim of this article is raising a question 'who is to blame' giving some examples of poor performance of the prospective English language teachers, some factors causing this and ways of attracting quality intake to the teacher education courses. The information used in the analysis has been taken from the answer books, randomly snatched up from ten different small packages of the B.Ed. campus of different parts of the country. The writing performances have been compared with the objectives specified to grade nine and ten by the Secondary Education Curriculum 2071 B.S. It was found that the prospective teachers are weak not only in using the language mechanism but they are also very weak in understanding the content as well as producing the organized, coherent writing.
\end{abstract}

Key words: Curriculum, syllabus, writing performance, specialized subject.

\section{INTRODUCTION}

Learning English language has become one of the most important and attractive areas in this globalized world. People all over the world are crazy to learn this language as a second or foreign language for many reasons. English is the most commonly used language in the world because it is believed that one out of at least five people can speak or understand it (Craith, 2007, p.141) English is the language of science and technology, computer, civil aviation, diplomacy and tourism. Possession of good English competence increases the chances of availing better jobs in multinational companies within the home country or of finding easy work abroad (Isik, 2008, p 123). English language learning is not only important because of being one of the UN languages, but it is also the language of mass media because most of the internationally recognized books, journals, periodicals as well as other media like films, songs, etc. are in English language. In short, English is the language of international communication and business,

* Dr. Rijal is an Associate Professor, Mahendra Ratna Campus, Tahachal, TU. 
higher studies, science and mass media, diplomacy and entertainment as well as the major language of the internet and websites.

Realizing the importance of it, every country of the world has introduced this language as a compulsory as well as the specialized subject in their syllabus from the very beginning of the schooling. In this context, the Secondary Education Curriculum of Nepal, CDC (2071 B.S.) has mentioned: "English is the principal international language of diplomacy, knowledge, business and tourism" (p. 1). It has further added that it has a dominant position in international media, science and modern technology.

In the curriculum, it has been mentioned that learning of English opens up the world for the children and youth giving them the ability to become active participants in the knowledge making society and raises their awareness of the multilingual and multicultural world they live in. The curriculum for grade ix and $\mathrm{x}$ English has given level-wise as well as class-wise and skill-wise competencies. In addition to understanding, using spoken English for general purposes, interacting, communicating and collaborating and reading a range of fiction and non-fiction texts, the students of secondary level will be able to write descriptive, narrative and imaginative texts at the end of this level. The syllabus has expected from the students of secondary level to write comprehensible, accurate and standard sentences. The general English syllabus has been designed to give the students confidence to communicate effectively in real life situations.

However, after passing even the plus two level (equivalent to certificate level), the students of major English of B.Ed. level can be seen very weak in forming standard English sentences, choosing appropriate vocabulary, putting their ideas in well, coherent paragraphs and using the appropriate mechanisms. They are found to have written some senseless sentences, with repetition, without caring for the spelling and punctuation marks. This article has tried to raise a genuine question 'Who is to blame?' for the failure behind the learners' performances and abilities.

\section{METHODOLOGY}

The information to be analyzed in this research study was taken from the answer books of the examination of B.Ed. $1^{\text {st }}$ year 'Foundations of Language and Linguistics' (Eng. Ed. 416) held in 2074. In course of paper checking, I found in almost all papers some meaningless writing, so, the question arose in my mind, how such students came up to this level choosing English as their specialized subject. So before marking the 
papers, I chose a question, 'What is synonym? Describe any two types of synonym (question no 5.)' Then, from the bundles of ten different campuses, I randomly snatched up ten copies and took photos of the answer no. 5 through cell phone camera. Some of the examples have also been mentioned in the following paragraphs as the observational data with the description and explanation of them. The performances of the students have been compared with the objectives of secondary level as mentioned in the Secondary Education Curriculum 2071 B.S.

\section{ANALYSIS AND RESULT}

In Nepal there are not any native English speaking students who choose English as a major subject at B.Ed. level. If the candidates want to study English at this level, they should be able to show that their English is good enough for them to successfully complete the courses offered by the university. However, in the Nepalese context, because of the political forces through student union, the entrance tests can not be taken by the students, so the students who write like the following extract can get admission every year at this level.

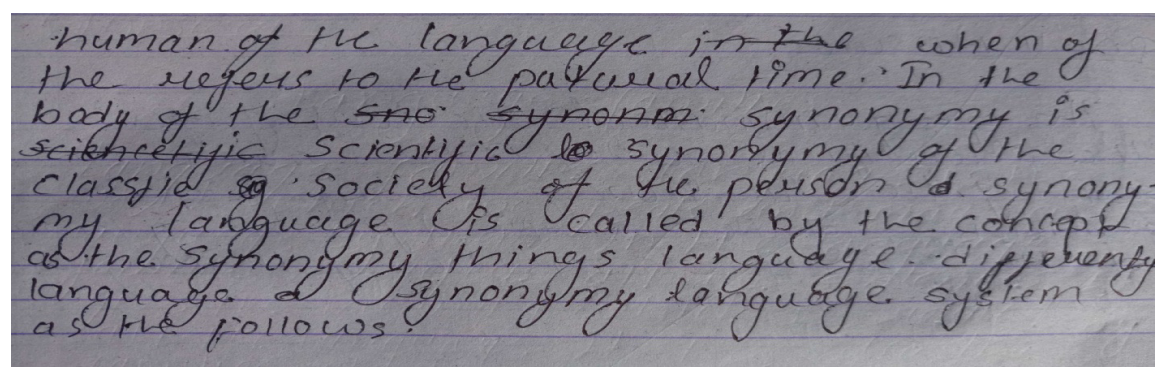

The writing of this extract shows that the candidate has neither understood the question nor he/she has written even a single meaningful sentence. This shows that, because of the lack of any standard entrance test, those students who do not have the minimum ability to study English subject have been admitted in the major English courses. It has hampered both the candidate himself/herself as well as the classes because the candidate never passes the examination, on the one hand, and the teachers are also not able to get them to understand the content and meaning of the thing taught in the classroom on the other.

The grade nine English syllabuses has mentioned that students will develop writing process to enhance their written products (p. 60) by planning and organizing ideas for writing; by revising and checking 
structures, spelling and punctuation as well as by practicing in peer group and self- editing to improve writing conventions.

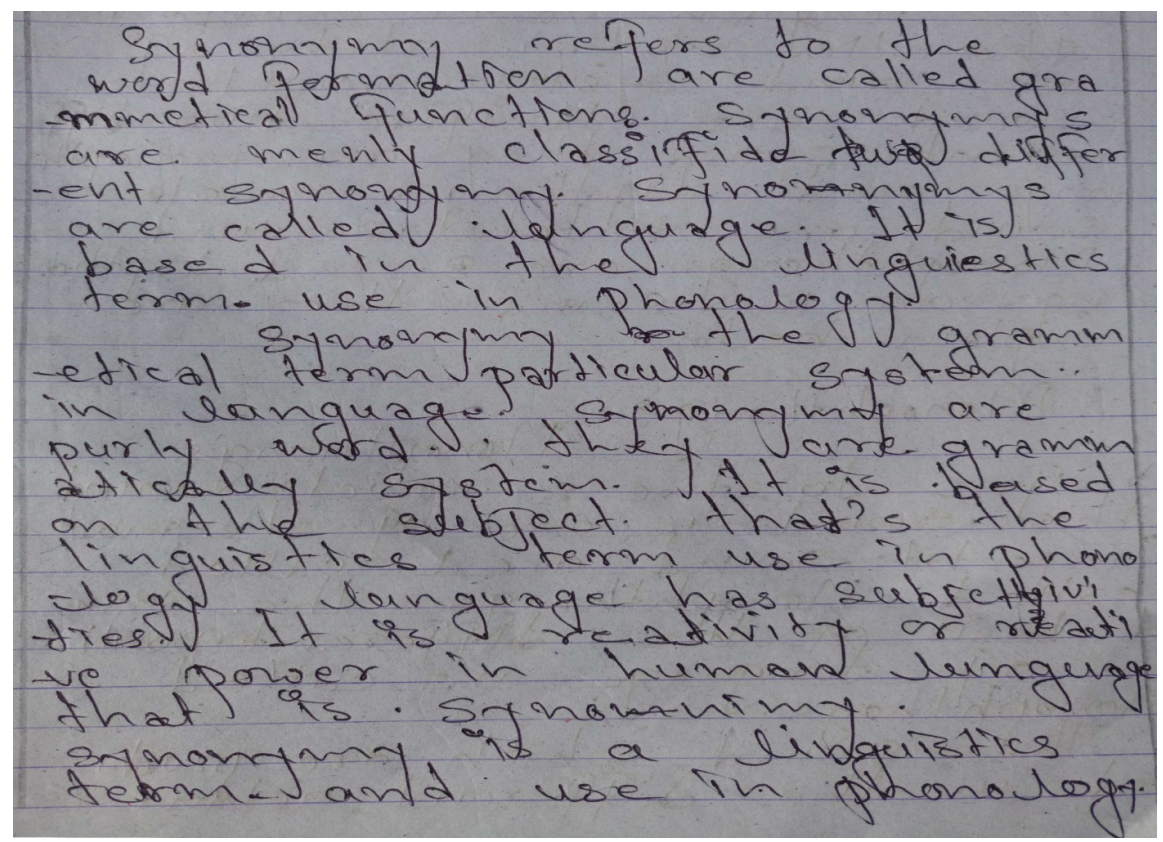

When we observe the above extract, it can be said that the planning and organizing ideas, revising and checking structures, spelling and punctuation are unknown to the students. This shows that this student of B.Ed. level is not able to show the quality of grade nine students as expected in the course syllabus.

One of the grade-wise objectives of reading of grade nine is constructing meaning from reading short texts in written, printed or digital forms.

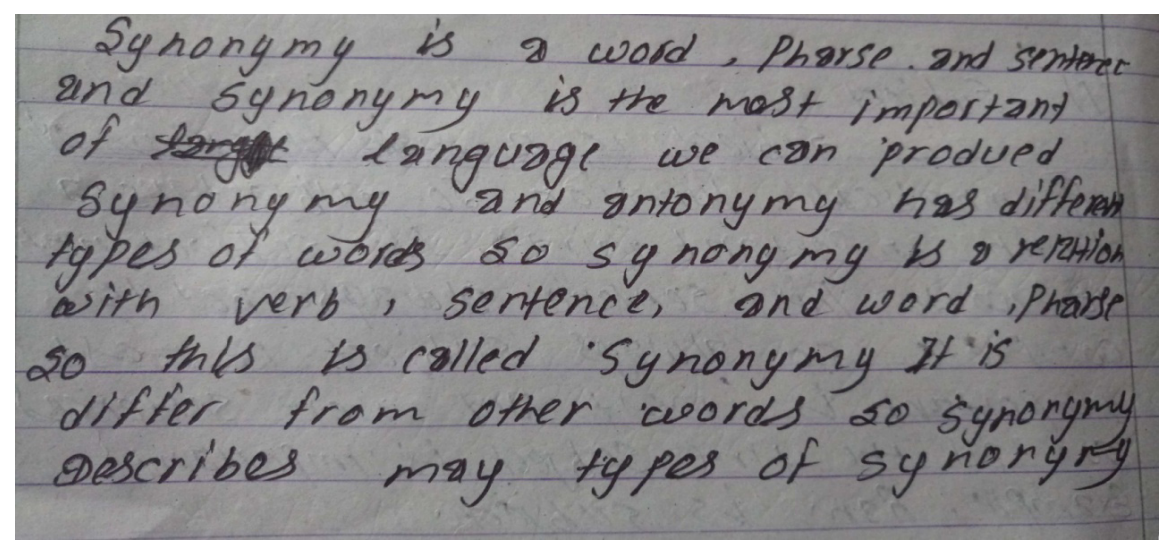


This extract reveals the fact that the student of B.Ed. level has not understood the written text about synonyms and their types. If the student has understood the written text about the taught or read content, he/she would not have written such sentences like "synonym is a word, phrase and sentence and...." This means that he/she cannot grasp the meaning of what he/she reads from the text.

The writing objectives of class nine include: developing simple paragraphs using appropriate cohesive devises and transitions. If we observe the following extract, can we find these qualities? This is the writing of the B.Ed. major English student who is going to be the English teacher in the near future to teach the same class.

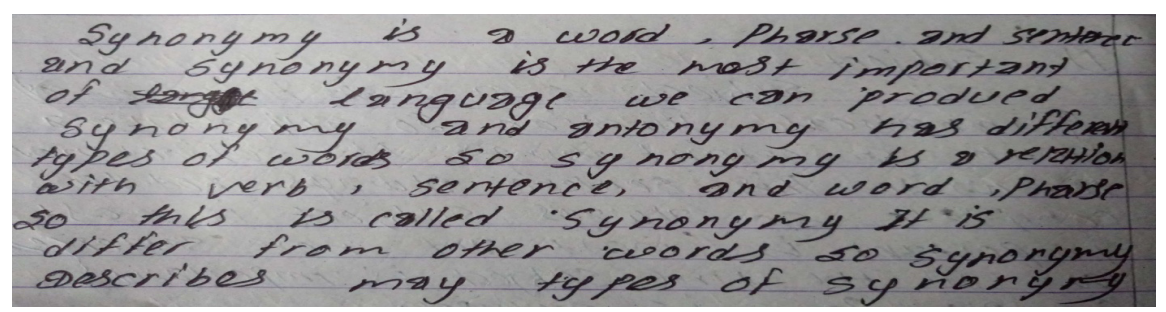

This evidence shows that the student cannot demonstrate awareness of the practices to develop paragraphs using appropriate cohesive devices and transitions. Even the class ten students are expected to use the relationship between particular words (e.g. synonym/antonym, cause/effect, part/whole, item/category) to better understand each of the words. However, the above extract can be the evidence of not grasping the etymological meaning of 'synonym' and 'antonym'. This indicates that the students knowing even no meaning at all can also be promoted for the higher level.

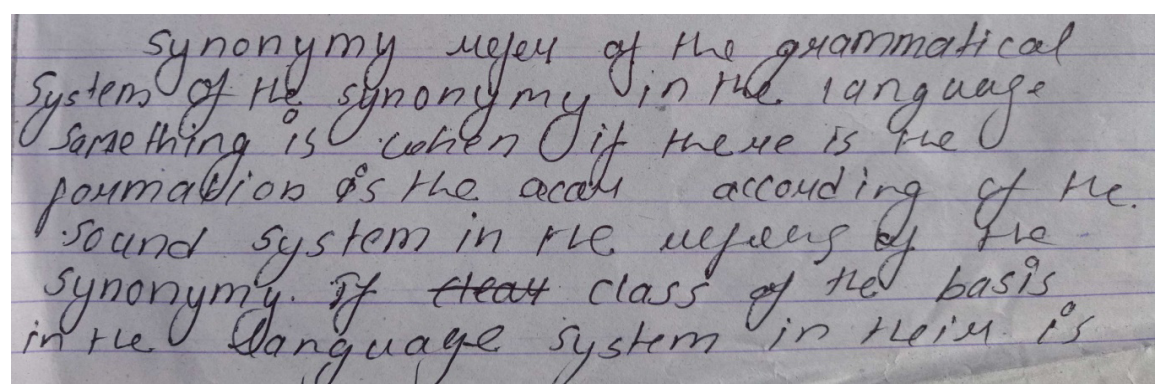

Such examples lead us to think how these students got pass marks in the SLC examination as well as the examinations of plus- two levels. Is 


\section{WHO IS TO BLAME}

there any provision of giving grace marks in the plus two examinations or is there any provision of promoting students up if they could not secure pass marks in some subjects? Otherwise how could they reach the B.Ed. level offering English as a major subject?

What can the examiner conclude from the extracts given below in which the examinee has neither used any main verb nor differentiates between 'it,' 'it is' and 'its.' The students' writing in these selected samples shows that they are weak not only in understanding the contents but also in producing the correct agreements with sentences like: 'synonym is a sentences', 'synonym is a scientifices,' as seen in this extract:

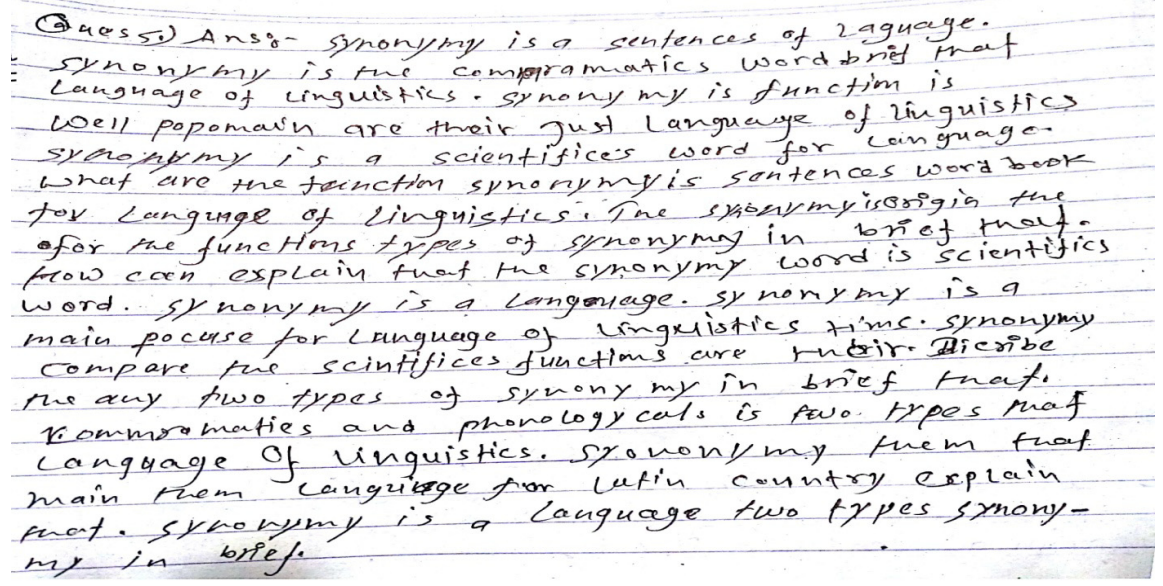

All these extracts and their analysis show that there is something wrong from the policy level to practices including every stakeholder of the teacher education. There might be several reasons like providing students chances for appearing in the reexaminations in SLC/SEE as well as plus two levels, exam paper checking in the halls, scrutiny by politically recommended teachers, undue political force for students' admission, students' irregularity at the higher level, lack of entrance tests of Bachelor level, mushrooming in teacher education colleges throughout the country, lack of stipend and scholarship for the poor and intelligent students for the admission of teacher education courses, etc.

At the time of result publication of SLC (Now SEE) examination, the notice for the re-examination is given for the students who have not obtained minimum pass marks in two subjects. This is the same case for plus two level examinations. The students do not have to take so much trouble 
in filling up the forms. From one point of view, this can be okay for those genuine students who have missed their chance of securing good marks in the examination but for those students who are weak in the failed subject, this can be the escape route because in the chance examination neither the examination is held with so much care nor are the examination papers are checked so seriously. It always seems to give the students a chance to be promoted to the higher level.

There seem to be four categories of students in terms of their exam results. The first category of students usually gets admission in science faculty after their SLC (SEE). The second category of the students gets admission in the management stream. The third category of them usually takes their admission in some prosperous humanities subjects like literature, mathematics, computer science and mass communication. It can be seen that the fourth category goes to the education stream. In the beginning of the plus two session, the classes of humanitities and education streams are almost nil but after the result publication of the chance examination, they take the admission of the students. This shows that the only weaker students get admission in the humanities and education streams. These very processes and incidents can be seen during the admission of B.Ed. and B.A. levels.

Furthermore, there are more than eight hundred affiliated education campuses of Tribhuvan University which dire need the students to admit and survive and sustain these campuses. In many places, the students' exam papers show that they are involved in mass cheating because in the exam papers the examiners can find every paper started with the same letter, words, and mechanics and commit the same type of mistakes throughout the package. This is either because of the colleges or schools themselves or because of the negligence of the superintendent and observers. In many places because of the political instability and undue dominance, the community itself is involved in undue work in the examination.

The paper checking of the exams have been carrying out in the specified halls of the District Education Co-ordination Offices or National Education Examination Board. The examiners are neither given scoring keys or any orientation of in-depth paper checking. Many of the teachers who have never taught those subjects also go to the hall for paper checking. The 'monsoon and BHANSUN' also gets its hands over the other criteria. Furthermore, many of the examiners mark the papers average scores 


\section{WHO IS TO BLAME}

without going through them in detail. There might be two reasons for this - one if they score average, the scrutiny does not focus its attention toward the average marks and the other, if their counterparts are doing their job superficially, why do they have to go in-depth. Doing this, many of the genuine students have been suffering from injustice and those weak students who produce senseless writing also get average marks. Furthermore, the examination office personnel also encourage the examiners to be liberal as far as possible. It can be heard that an examiner can check more than 180 copies a day. How can it be possible if he/she checks the copies going through minutely, putting the marks on the front page of the paper and filling up the marks file and completing all these 180 papers from 10 o'clock to 5 o'clock in the evening?

The members of the scrutiny board are also recommended by political force. They are neither responsible to the group leader nor are so serious in their work because their recommendation is not based on the intellectual criteria or ability of their work, secrecy and accountability of their work. Most of the time, they are in a hurry for completing their assigned task. If there are any inconsistencies and difficulties, they are not ready to correct them but avoid it by neglecting it immediately. The officials are also very helpless in front of the politically recommended members of the board in forcing them to perform their job genuinely.

The admission process of the students for the teacher education courses at B.Ed. level takes place without involving them in the entrance tests because of the undue force of student union. So, those who have secured marks by any hooks and crooks get chances of being admitted to any subject. From the very first day of the college life, both the students as well as the teachers have to suffer because of it very much. On the one hand, the students never pass the level and on the other, the classes are not so effective because of such weak students in the classrooms. Furthermore, when the students do not understand what the content is delivered in the classroom, they remain irregular and try some undue means in the tests. On the other hand, teachers are accused of not being effective enough to maintain the sound academic environment.

The examination of the Tribhuvan University and paper checking are not unscathed by the negative effects of paper checking of plus- two level at a conference hall. On the one hand, because of the ill influence of paper checking of plus- two level, the university teachers also do not check 
the papers genuinely and seriously. On the other hand, the examination controller's office has set the time bound of twenty days for one packet, 27 days for two packets and so on which has also encouraged the examiners to finish the papers in haste and make many absurdities. Moreover, most of the teachers who have been teaching in the plus- two levels are also teaching at campus level and checking the examination papers in the same style as they do in the plus-two level.

The above mentioned extracts are the writing performances of the prospective English language teachers of secondary schools. They have already received the minimum qualification for Basic Level of Education. Perhaps, some of them have also been teaching at this level of different parts of the country. If the English teachers are of this kind at the basic level, we can imagine what quality product we are giving from the very beginning of the schooling. One of the reasons for this might be that the education faculty has lost its grip of attracting better students because of the lack of scholarship and stipend schemes which were introduced in the past (2028 B.S.) education program, but now this program has neither been dismissed nor reformed in line with the reformation of student tuition fees.

In view of Cole (1999) "In order to obtain qualified teacher status, teachers of secondary level now are required to demonstrate that they have working knowledge of a number area" ( $p$ iv). If such teachers are given the chances to handle the classes, can they perform as expected? Similarly, McCann, Jones and Aronoff (2012, p. 13) state that teachers have to make decisions about the match between goals, materials and activities for a group of learners and reflect on the effect of decisions in order to inform further decisions. In such cases, if the weak intake for the education stream is taken, can the goal of effective teaching be achieved? It is believed that the quality of teaching in the classrooms is the single most important factor in advancing student achievement and in sustaining school improvement (McCann, Jones and Aronoff, 2012, p. xi). So, high quality teachers are a must which can be achieved if the quality intake is attracted to the education stream or teacher education courses through various schemes like scholarship, higher salary, grading, etc.

\section{CONCLUSION}

In nutshell, the weakness in the teacher education is not associated with only one institution or stakeholder. It can be seen from the very top policy level which has provisioned the change examination or re- 
examination after the SLC/SEE and +2 level examination to the practice level in which the admission to teacher education courses are taken without any qualifying subject-wise entrance tests. The examination system and the paper checking processes are also equally responsible to make the examiners superficial and unscrupulous. Furthermore, the government is also reluctant to introduce reformation in education system which can create opportunities of job guarantee for the people which can also minimize the foreign alienations of both skilled as well as unskilled human resources every year. That is why I would like to ask "Who is to blame"?

\section{REFERENCES}

CDC. (2071). Secondary Education Curriculum Class 9-10. Sanothimi, Bhaktapur: Author.

Cole, M. (Ed.) (1999). Professional issues for teachers and student teachers. London: David Fulton Publishers.

Craith, M. N. (Ed.) (2007). Language, power and identity politics. New York: Palgrave Mc Millan.

Isik, A. (2008). Linguistic imperialism and foreign language teaching. The Journal of ASIA TEFL vol. 5. 123-144.

Mc Cann, M., Jones, A.C \& Aronoff, G.A. (2012). Teaching matters most. New Delhi: Sage Advantage.

Wallace, M. J. (2010). Training foreign language teachers. Cambridge: Cambridge University Press. 